\title{
Legal Effects of Link Sharing in Social Networks
}

\author{
Eugenio Gil López ${ }^{1}$, Andrés G. Castillo Sanz ${ }^{2}$ \\ ${ }^{1}$ Department of Computer Science, Pontifical University of Salamanca, Salamanca, Spain \\ ${ }^{2}$ ESIT, International University of La Rioja, Logroño, Spain
}

\begin{abstract}
Knowledge sharing among individuals has changed deeply with the advent of social networks in the environment of Web 2.0. Every user has the possibility of publishing what he or she deems of interest for their audience, regardless of the origin or authorship of the piece of knowledge. It is generally accepted that as the user is sharing a link to a document or video, for example, without getting paid for it, there is no point in worrying about the rights of the original author. It seems that the concepts of authorship and originality is about to disappear as promised the structuralists fifty years ago. Nevertheless the legal system has not changed, nor have the economic interests concerned. This paper explores the last developments of the legal system concerning these issues
\end{abstract}

Keywords - Links In Social Networks, Rights Of Knowledge Sharing, Web 2.0.

\section{INTRODUCTION}

$\mathrm{T}$ HE year 2014 has come to resolve an important issue in relation to

the regime for the protection of copyright in the Internet, since two decisions of the Court of Justice of the European Union (in later CJEU) have been published, which have tried to clarify as much as possible whether there is any violation of the right of public communication in the case of links that lead to works of intellectual property without authorization.

These are both the sentences of February 132014 of the Fourth Chamber of the European Court of Justice in the Svensson[1] case and the sentences of October 212014 of the Ninth Chamber in the Bestwater [2] case. Both resolutions should be related to the recent reform of Spanish intellectual property law by means of the law 21/2014 of 4 November, with effects from year 2015.

In order to place all in the context we are situated, we must bear in mind that unto the author of a work with intellectual property the Revised Text of the Law of Intellectual Property (in later TRLPI) gives two types of rights, on the one hand the moral rights (article 14 TRLPI) and the other hand rights of property or exploitation (articles 17 et seq. of our revised text). The existence of these moral rights is emerging as one of the essential differences to Anglo-Saxon copyright law, where the absence of these rights results in that their defense may only happen in a contractual manner, and, in the absence of clause containing them, these moral rights from article 14 cannot be alleged.

This right, subject of controversy in the two aforementioned sentences, is integrated into the exploitation or heritage rights and it was already envisaged in the Berne Convention of 1886 for the protection of literary and artistic works in its articles 11, 11Bis and 11Ter. Interestingly, these articles do not use the designation of public communication (although they mention the right of transformation or translation), but this expression is used when a reference in article 11Bis to the "... public communication by means of loudspeaker..." is made.
Perhaps as heir to this agreement, the Directive 2001/29 of the European Parliament and of the Council of 22 May 2001 on the harmonization of certain aspects of copyright and other rights related to copyright in the information society, does not define in paragraph 1 of article 3[1], what there must be understood by a right to public communication, and therefore many problems, which we are faced with nowadays, come from there.

\section{PUBliC COMMUNICATION IN LEGAL ENVIRONMENT}

This precept tries to differentiate between 2 assumptions included in the field of public communication. On the one hand that which is generally called communication to the public, and on the other hand a concept more reduced and included within the first such as the right of making available.

Both issues are also regulated in our TRLPI, albeit with the novelty that a definition of public communication is given here. Article 20 states "that by public communication it would be understood any action whereby a plurality of people could have access to the work, without prior distribution of copies to each of them".

On the basis of these considerations it had been raised in the aforementioned two resolutions the question if the act of putting on a page a link on which you can click, and which takes us back to another page containing a work which is subject to copyright, does violate or not the right of public communication of the author. In both cases there is a prejudicial question posed to the European Court of Justice, in the first case by a Swedish court (case Svensson), and in the second (Bestwater) by a German court.

The issue is important because the use of including links to other resources is one of the bases of Internet and if the Court finds that there is infringement there, it would have hampered extremely that activity of adding links, because anybody can see the practical difficulties associated with the need to obtain the permission of the owners whenever a link should be included in a web page [3].

The first of the cases refers to journalistic publications communicated through the website of a newspaper in which two holders of rights on them work, and the second one arises from a promotional video of a company that is posted on youtube without authorization from their authors and that it is later linked on the website of competitors using the technique of framing or transclusion. Regardless now of the differences between the 2 cases, we are going to analyze quickly the conclusions of the European Court of Justice.

The Court differentiates 2 concepts in the right to public communication, on the one hand the communication and on the other its character of being public. Regarding the first issue, the European Court of Justice defends that an act of communication takes place in the form of making available through the links, and the Court expresses the same terms in the Bestwater case referring to what is affirmed in this sentence. 
Therefore, as it can be derived from article 3, paragraph 1, of Directive 2001/29, in order that there exists an Act of communication, it is sufficient that the work would be made available to the public, in such a way that their members could have access to it, being not decisive that such persons make use or not of that possibility.

On the second question, that communication would become public; the European Court of Justice says that "the protected work must be effectively communicated to a «public». For the purposes of article 3, paragraph 1, of Directive 2001/29, the term public refers to an indeterminate number of potential recipients and, moreover, involves a considerable number of persons".

This is what happens in the case of web links, and therefore we would be faced with a communication of the work to the public. However the Court points out that an authorization by the author is not required since in order for their asking so, the recipients of the work should conform a new public which should be different from the one who could have accessed the work potentially in its original location. Since the potential audience of the first communication is logically all Internet users, the audience to which the links are directed, are in essence the same, since on the first page there was no restrictive measure for the access by the users. The first obtained conclusion is clear; the linking with the indicated requirements is not a copyright infringement.

\section{The Spanish Intellectual Property LaW ReForm}

From January 1st of this year 2015 has entered into force the reform of our intellectual property law through the law 21/2014 4 November [4]. There are many issues facing this reform (especially in the rights management procedures), but we will focus essentially on two points that affect directly the issue we are dealing with.

First of all we will stop at the regulation known as rate Google or its technical name AEDE Canon. The cited rule establishes:

"The making available to the public by electronic providers of aggregation of content of non-significant fragments of content, reported in periodicals or on regularly updated websites which have an informative, a creation of public opinion or an entertainment purpose, shall not require authorization, without prejudice to the right of the editor or, in its case, to other holders of rights to receive fair compensation. This right shall be inalienable and it will be effective through intellectual property rights management bodies. "

This rule is about such services as Google News or Digg, because what they do is basically to establish links to other media news. They could continue doing it, but they should pay to the publishers the corresponding compensation.

Now, if, as we have seen above, the activity of linking with the analyzed requisites is lawful, we must ask ourselves to what extent the payment of this compensation is lawful too. We must also think that the existence of these news aggregators is beneficial to publishers in the majority of cases, since much of the traffic that gets to them is through those links, and that results in page access and ultimately in contracts of advertising.

About the regulation of this issue, it must be said that the experience shown by other neighboring countries has served very little. In 2007 a similar procedure was initiated in Belgium under the name of Copiepresse case [5], in which this Association of publishers of newspapers was facing against Google. The Belgian courts gave reason to Copiepresse considering that it violated the right of reproduction and the communication to the public, and Google was forced to cancel its linking activities in this country. The funny thing is that about two months later, the same entity felt obliged to ask Google to resume its activity in the face of the decline in visits to the portals of their affiliates. What seems clear is that what the Belgian editors wanted was not to stop appearing in the search engine, but to continue appearing and charging. Google response was very clear, all or nothing, or appear without charging or not listed. The backing down of the editors had got to give reason to the American giant.

Something similar has happened in France, although with the peculiarity that, in view of what already happened in Belgium, the precaution was taken of qualifying legally this compensation as waivable, which has allowed the newspapers to decide if it compensates them or not the activity offered by Google. In fact, the search engine will maintain full access to the content of the news editors and in return it will make a contribution of EUR 60 million to finance projects of digital media of French publishers.

These experiences should serve as a reference for future conflicts between Google and publishers from different countries, but in the Spanish case and ignoring what happened in the neighboring country, the voluntary resignation of the editors to it has been tried to be avoided by establishing legally the charging of this canon to be indispensable, which results in benefit of the corresponding rights management body. Thus once more the facts are showing that the management entities, far from being entities that comply with its obligation to promote culture (understanding within it, as it can not be otherwise, science and technology), are lobbies who currently occupy the role that in the Illustration was occupied by the Church [6].

It is one more try of these management bodies to look for compensation for the reduction of their incomes as a result of the expansion of the digital technology in the terms of copyright, and that intent was already evident in other areas such as $\mathrm{p} 2 \mathrm{p}$ networks, where they have acted against the users of these networks [7][13].

We found the main problem about this issue in the poor drafting of the precept and the lack of clarity in what it wants to regulate. We will focus our criticism mainly on two issues.

On the one hand, the expression 'no significant fragment' could clearly be improved from the point of view of legal technique (whilst unknown in the intellectual property laws of countries of our environment).If we give the consideration of non-significant to the fragment, this limits the objective reasons for charging a compensation. It seems that it does not lead to appreciable harm that could justify charging for it. Therefore it seems illogical that if the European Court of Justice have come to recognize that the inclusion of contents of free access on the Internet in a different web site, through the technique of framing, is not a public communication and therefore it can be implemented, with more reason this activity can be made in relation to a snippet of the work. It seems clear that it is more damaging to the author to provide access to the work as a whole than to mere fragments of it.

On the other hand and in accordance with which was stated above, the qualification of this rate as fair compensation, and therefore forced collection through management bodies, excludes from itself the general and original operation of copyright: the author is the center of the intellectual property and as such he can decide both to charge for the use or exploitation of his work, and to give it away for free, without thereby limiting his creator status in any way. This second possibility is being limited deliberately through the drafting of the precept contained in our rule.

Relating all these issues with the interpretation established by the ECJ in the cited cases, there is no doubt for us that under no circumstances we would be faced with a breach of the right of public communication of the author in the activity of these portals. If there is not such a possibility in the analyzed cases, we could hardly find it in the activity from Google News. With this situation in mind we need to ask ourselves if we are violating another right of the author, such as 
the right of reproduction. This is a different question, because in many cases a reproduction in the servers of the linker is indeed being made, so just as David Maeztu [80] rightly indicates, insofar as a reproduction is not played via link on the local servers, there will be no problem. It would therefore be enough to modify portals such as Google News to display directly the text without reproducing it on their servers, to make this tax to be meaningless.

An interesting issue related to this (though we will leave it to a future work) would be to analyze the possibilities that exist to get know previously if we are violating these rights on the part of the news portal, which leads us to analyze the relationship between law and artificial intelligence, or in other words, the possibility of applying to these cases criteria of artificial intelligence, which could permit us to discriminate, from a legal perspective, those offending cases of those which are not, by means of the application of reasoning and legal ontology. By the end of the sixties a series of artefacts came out which were called mostly legal expert systems, although the term was coined already in the mid-1950s in the field of Artificial Intelligence by the professor of Standford John McCarthy.

There have been several developments and works around the entailment between AI and law, which have focused not only on search management in document databases, but also in areas like legal decision taking or in the creation and development of legislative systems.

About the issue of this paper, the difficulties in the application of AI come from three aspects [9]:

- The system should recognize that the user query is formulated in legal language

- It should contain a computerized expression of the applicable legal rules

- It must bring online these rules together with the query, draw a conclusion and provide a legal response.

The difficulties in fulfilling these three requirements, which are based on the characteristics of legal language, which is interpretable and ambiguous, limit greatly the chances of success of these systems. In the same way that it is done in the field of education, the results depend on having sufficient data on carried out assessments, and the possibility of detecting anomalous behaviors in the development of new preventive and corrective actions [10]. Perhaps in this field and because of the described circumstances, the claims to carry out a reproduction of the human brain should be limited, and the focus should be put on the development of tools for the analysis of vast amounts of information, and so provide recommended guidelines, which in any case must be analyzed and contrasted by the human intellect to handle the actual postulation. It must be taken into account in any case that the definition of analytics have gone further in recent years, however, to incorporate elements of operations research, such as decision trees and strategy maps to establish predictive models and to determine probabilities for certain courses of action [11].

\section{The Regulation of Webs With Links}

Another issue that the effects of the two resolutions that give cause for this work have been intended to apply on is the treatment that should be given to the pages of links that allow carrying out the downloading of protected works without counting with the appropriate rights.

We shall not dwell now in the evolution suffered by our jurisprudence in the legal qualification of these actions. Although we can say that, while in a first moment our courts defended that the activity of these sites did not constitute a crime against intellectual property, nowadays "the resolutions that consider that a offence is committed against copyright in the case of web pages with links to $\mathrm{P} 2 \mathrm{P}$ networks, in which the owner of the website goes into the file-sharing site, extract from it a link to a particular file, film, music or other work, and incorporates it as a direct download element in his own website, without showing whatever information about the exchange type, so the user accesses the content directly from the page, have a greater legal weight "[12].

In relation with these pages the issue of the application of the criterion established by the European Court of Justice, and therefore their possible legality as an act of linking to intellectual property works, is raised. However, it seems clear as a matter of fact, that we do not assume the same course, since in these cases the link will not provide directly the work, but it is an instrument through which, and following a series of steps, we can finally access the work. For example in the case of $p 2 p$ networks, the access to a work is completed by means of communication protocols and the download of specific software that allows us to get hold of the work in question, which clearly exceeds the mere activity of linking, which the CJEU makes reference to.

\section{Conclusion}

One of the issues that is more striking in the analyzed issue is the disconnection in some respects between the Spanish legislator and the decisions of the European Court of Justice. It is in fact a much more expensive point if (as in this case) the judgment is prior to the enactment of the concerned regulation. This has led to, that in the case that we deal on; it has even been declared that the Google tax established by the law of November 2014 is quite dead before birth.

And why is it so? It is due basically to the subjugation of our legislators (and by extension of the political power) to the guidelines and requirements of the management entities of intellectual property rights. These institutions had been marked as a result of the judicial procedures initiated against them on the basis of the bad administration of their funds in a not-too-distant time.

But it is not the first time that this situation occurs. In 2014 the CJEU had to admonish Spain because of the enforcement that was being made of the famous digital canon regulation. That enforcement was based on a single idea, such as it was the huge collection through this concept, by means of a establishing of an indiscriminate system that was contrary to the legal reality, which has recently got to be amended by imperative of the CJEU.

It seems clear that the rights management entities play a role, and that anyone who wishes to, can make use of them to carry out the management of the rights that the law grants. But we must not forget that the central figure of this system is the author and not the management entity, which often endorses the position of the first and gives the feeling that outside them there is nothing in the field of intellectual property, whilst in reality just the contrary is true: The best and most rewarding, that is the authors, their works and above all the freedom of the designer in the exercise of his rights, is outside them.

The Web 2.0 is changing our society without doubt. But not all parts of are cultural, economic and social system have the same adaptability. We are living "in interesting times", and we are bound to see how new paths will be tried for social change from individuals, communities and institutions.

If projects such as [14] and [15] will be connected with Web 2.0, the experience would also be incredible. It would stimulate to increase the adaptability, with these new paths explained in previous paragraph, in other knowledge areas.

\section{REFERENCES}

[1] Sentencia del Tribunal de Justicia de la Unión Europea de 13 de febrero de $2014 »$. En el asunto C-466/12. [Online].

[2] http://curia.europa.eu/juris/liste.jsf?pro $=\&$ nat $=$ or $\&$ oqp $=\&$ dates $=\& l g=\& l a$ nguage $=$ es $\&$ jur $=\mathrm{C} \% 2 \mathrm{CT} \% 2 \mathrm{CF} \&$ cit $=$ none $\% 252 \mathrm{CC} \% 252 \mathrm{CCJ} \% 252 \mathrm{CR} \%$ 
$252 \mathrm{C} 2008 \mathrm{E} \% 252 \mathrm{C} \% 252 \mathrm{C} \% 252 \mathrm{C} \% 252 \mathrm{C} \% 252 \mathrm{C} \% 252 \mathrm{C} \% 252 \mathrm{C} \% 252 \mathrm{C}$ $\% 252 \mathrm{C} \% 252 \mathrm{Ctrue} \% 252 \mathrm{Cfalse} \% 252 \mathrm{Cfalse} \&$ num $=\mathrm{C}-466 \% 252 \mathrm{~F} 12 \& \mathrm{td}=$ $\% 3$ BALL\&pcs $=$ Oor\&avg $=\&$ page $=1 \&$ mat $=$ or $\&$ jge $=\&$ for $=\&$ cid $=331915$

[3] Sentencia del Tribunal de Justicia de la Unión Europea de 21 de octubre de 2014. [Online].

[4] http://curia.europa.eu/juris/liste.jsf?pro $=\& \operatorname{lgrec}=$ es $\&$ nat $=$ or\&oqp $=\&$ da tes $=\&$ lg $=\&$ language $=$ es $\&$ jur $=\mathrm{C} \% 2 \mathrm{CT} \% 2 \mathrm{CF} \& \mathrm{cit}=$ none $\% 252 \mathrm{CC} \% 252$ CCJ\%252CR $\% 252 \mathrm{C} 2008 \mathrm{E} \% 252 \mathrm{C} \% 252 \mathrm{C} \% 252 \mathrm{C} \% 252 \mathrm{C} \% 252 \mathrm{C} \% 252$ $\mathrm{C} \% 252 \mathrm{C} \% 252 \mathrm{C} \% 252 \mathrm{C} \% 252 \mathrm{Ctrue} \% 252 \mathrm{Cfalse} \% 252 \mathrm{Cfalse} \&$ num $=\mathrm{C}$ $348 \% 252 \mathrm{~F} 13 \& \mathrm{td}=\% 3 \mathrm{BALL} \& \mathrm{pcs}=$ Oor $\&$ avg $=\&$ page $=1 \&$ mat $=$ or $\& \mathrm{jge}=\&$ for $=\&$ cid $=331915$

[5] M. Iglesia Andrés de la (2014). Comentario a la sentencia del Tribunal de Justicia de la Unión Europea en al caso Svensson: sobre la naturaleza jurídica de los enlaces a obras protegidas pro derechos de. [Online]. Actualidad Jurídica Uría Menéndez /37-2014.

[6] http://www.uria.com/documentos/publicaciones/4269/documento/e08. pdf?id $=5461$.

[7] Ley21/2014 de 4 denoviembre dereforma de la Ley de Propiedad Intelectual. https://www.boe.es/diario_boe/txt.php?id=BOE-A-2014-11404

[8] http://www.copiepresse.be/

[9] J. Cueva González-Cotera de la (2014). El nuevo canon a las universidades: tras la apropiación del canon digital para las copias privadas, la del open Access. El profesional de la información, 2014, marzo-abril, v. 23, n. 2, p. 187.

[10] E. Gil López, A. Castillo Sanz (2013). Legal Issues Concerning P2P Exchange of Educational Materials and Their Impact on E-Learning Multi-Agent Systems, in International Journal of Interactive Multimedia and Artificial Intelligence, Vol. 2, June, pp. 73-78.

[11] D. Maeztu (2014). El canon EADE, muerto antes de nacer. Blog El derecho y las Normas [Online]. http://derechoynormas.blogspot.com. es/search?updated-min $=2014-01-01 \mathrm{~T} 00: 00: 00 \% 2 \mathrm{~B} 01: 00 \&$ updated$\max =2015-01-01 \mathrm{~T} 00: 00: 00 \% 2 \mathrm{~B} 01: 00 \&$ max-results $=50$.

[12] C. Fernández Hernández y Pierre Boulat (2015). Inteligencia Artificial y Derecho. Problemas y perspectivas. [Online].

[13] http://noticias.juridicas.com/conocimiento/articulos-doctrinales/9441inteligencia-artificial-y-derecho-problemas-y-perspectivas/

[14] J. Campo-Ávila del, R. Conejo, F. Triguero, R. Morales-Bueno (2015). Mining Web-based Educational Systems to Predict Student Learning Achievements, in International Journal of Interactive Multimedia and Artificial Intelligence, Vol. 3, No 2, pp. 49-54.

[15] A. G. Picciano (2014). Big Data and Learning Analytics in Blended Learning Environments: Benefits and Concerns, in International Journal of Interactive Multimedia and Artificial Intelligence, Vol. 2, $\mathrm{N}^{\mathrm{o}}$ 7, pp. 3543

[16] Sentencia de la Audiencia Provincial de Castellón de 12 de Noviembre de 2014. Fundamento Jurídico $3^{\circ}$.J. U. Duncombe, "Infrared navigationPart I: An assessment of feasibility (Periodical style)," IEEE Trans. Electron Devices, vol. ED-11, pp. 34-39, Jan. 1959.

[17] Gil, E., and A. Castillo-Sanz, "Legal Issues Concerning P2P Exchange of Educational Materials and Their Impact on E-Learning Multi-Agent Systems", International Journal of Interactive Multimedia and Artificial Intelligence, vol. 2, issue Regular Issue, no. 2, pp. 73-78, 06/2013. Abstract

[18] Lorezo, W., R. Gonzalez-Crespo, and A. Castillo-Sanz, "A Prototype for linear features generalization", International Journal of Artificial Intelligence and Interactive Multimedia, vol. 1, issue A Direct Path to Intelligent Tools, no. 3, pp. 59-65, 12/2010. Abstract

[19] Broncano, C. J., C. Pinilla, R. Gonzalez-Crespo, and A. Castillo-Sanz, "Relative Radiometric Normalization of Multitemporal images", International Journal of Artificial Intelligence and Interactive Multimedia, vol. 1, issue A Direct Path to Intelligent Tools, no. 3, pp. 53-58, 12/2010. Abstract

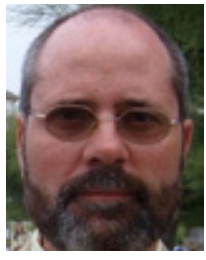

Andrés Castillo-Sanz was born in Madrid in 1964. He has degrees in Physics, Sociology and Theology from the Complutense University of Madrid. The doctoral degree was obtained in 2004 at the Pontifical University of Salamanca. He teaches at International University of La Rioja and Pontifical University of Salamanca. He is researcher in in the field of applied multiagent systems, health sciences and social movements. He also participates in several research groups on different Universities in Spain and other European countries.

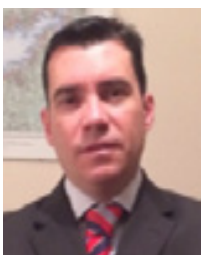

Eugenio Gil was born in Galicia (Spain) in 1972. He has a degree in Law from Deusto University in Spain. The doctoral degree was obtained in 2014 at the Pontifical University of Salamanca. He is researcher in Pontifical University of Salamanca (UPSA) and in International University of La Rioja (UNIR) in the field of Information Technologies Law. Actually he is the Academic Secretary at the School of Engineering and Architecture in Pontifical University of Salamanca, Madrid campus. 